\title{
In vivo growth-inhibition of Sarcoma 180 tumor by alginates from brown seaweed Sargassum vulgare
}

\author{
Alessandra Paula Alves de Sousa ${ }^{a}$, Márcia Rocha Torres a , Cláudia Pessoa a , \\ Manoel Odorico de Moraes ${ }^{a}$, Francisco Dário Rocha Filho ${ }^{b}$, \\ Ana Paula Negreiros Nunes Alves ${ }^{a}$, Letícia Veras Costa-Lotufo ${ }^{\text {a,* }}$ \\ ${ }^{a}$ Departamento de Fisiologia e Farmacologia, Faculdade de Medicina, Universidade Federal do Ceará, P. O. Box-3157, 60430-270 Fortaleza, Ceará, Brazil \\ ${ }^{\mathrm{b}}$ Laboratório de Patologia Prof. Livínio Pinheiro, Instituto do Câncer do Ceará, Fortaleza, Ceará, Brazil
}

Received 4 November 2005; accepted 29 August 2006

Available online 6 October 2006

\begin{abstract}
Previous studies had demonstrated that alginates from Sargassum sp. (Phaeophyta) showed a considerable activity against various murine tumors. The aim present study is to investigate the in vivo antitumor activity of two alginates (SVHV and SVLV) with different viscosity extracted from brown seaweed Sargassum vulgare C. Agardh against Sarcoma 180 cells transplanted in mice. Both alginates inhibited growth of sarcoma 180. The oral route of administration was more effective for both alginates, leading to an inhibition of 51.8 and $74.8 \%$ for SVLV at the doses of 50 and $100 \mathrm{mg} / \mathrm{m}^{2} /$ day, respectively, and of 66.2 and $88.8 \%$ for SVHV at the same doses. SVLV was 2.04 times more active after oral administration, while SVHV was 1.89 , both at the dose of $100 \mathrm{mg} / \mathrm{m}^{2} /$ day. Alginates-antitumor activity was related to the tumor proliferation rate inhibition, as observed by reduction of Ki67 staining in tumor of the treated-animals. The histopathological analysis of liver and kidney showed that both organs were affected by SVHV and SVLV treatment. However, only SVLV led to acute tubular necrosis. Alginates cause the enlargement of the white pulp of the spleen of treated animals, suggesting that the observed antitumor activity could be related to alginates immunomodulatory properties.
\end{abstract}

(C) 2006 Elsevier Ltd. All rights reserved.

Keywords: Alginate; Antitumor; Seaweed

\section{Introduction}

Seaweeds have caused an emerging interest in the biomedical area due to their content on pharmacologically bioactive substances with great chances to be employed against bacteria, viruses, other pathogens and tumors (Blunden, 1993; Ireland et al., 1993; Smit, 2004). Despite the ascending number of new findings about seaweed metabolites possessing biological activity on the last three decades few products having actual potential have been identified or developed (Smit, 2004). Among those substances that received most attention from pharmaceutical companies for development of new drugs are the sulfated polysaccha-

\footnotetext{
* Corresponding author. Tel.: +55 854009 8255; fax +55 8540098333.

E-mail address: 1vcosta@secrel.com.br (L.V. Costa-Lotufo).
}

rides (antitumors and antivirals), the halogenated furanones (antifouling compounds) and the kahalalide $\mathrm{F}$ (anticancer and anti-aids compounds) (reviewed by Smit, 2004).

Polysaccharides represent a very interesting class of macromolecules, widely spread in nature, and they have attracted more attention recently in the biochemical and medical areas due to their immunomodulatory and anticancer effects (Ooi \& Liu, 2000). In fact, seaweeds could be considered a great source of polysaccharides, which have attained commercial significance due to their physical properties such as gelling, water-retention and their ability to emulsify (Moe, Draget, Skjåk-Bræk, \& Smidsrød, 1995; Renn, 1997; Smit, 2004). In this context, alginates, structural components in marine brown algae (Phaeophyta), possessed a huge importance with an annual production of about 30,000 metric tons (Moe et al., 1995). 
Alginates are unbranched polymers of polysaccharide with gel-forming properties composed of $\beta$-(1-4)-D-mannuronic acid (M), $\alpha$-(1-4)-L-guluronic acid $(G)$ and alternating (MG) blocks (Moe et al., 1995). Alginates are used as ingredients in food, pharmaceuticals and diverse consumer products and industrial processes (Moe et al., 1995). They present many biomedical and biotechnological applications. They have been used for immobilization of Langerhans islets in the treatment of experimental diabetes mellitus in rats (Fan et al., 1990; Tze \& Tai, 1982) and for microencapsulation of hormone-producing cell for the treatment of diabetes mellitus and parathyroid disease (Darquy \& Sun, 1987; SoonShiong et al., 1994). It has been shown that alginates led to monocytes and macrophages stimulation, resulting in an increase of cytokine production (Otterlei et al., 1991; Son, Moon, Rhee, \& Pyo, 2001; Thomas, Harding, \& Moore, 2000). The macrophage stimulation seems to be related to alginates ability to enhance the healing process (Thomas et al., 2000). Experimental data suggested that low-molecular weight alginates could be useful in the prevention of obesity, hypercholesterolemia, and diabetes (Kimura, Watanabe, \& Okuda, 1996). Alginates also presented anticoagulant activity (Ronghua, Yumin, \& Jianhong, 2003).

Concerning antitumor activity, alginates from Sargassum sp. (Phaeophyta) showed a considerable activity against various murine tumors, such as Sarcoma 180 (solid and ascitic types), Ehrlich ascites carcinoma and IMC carcinoma (Fujiihara, Izimma, Yamamoto, \& Nagumo, 1984; Fujiihara \& Nagumo, 1992, 1993). Fujiihara and Nagumo $(1992,1993)$ suggested that the antitumor activity is highly influenced by the composition of the homopolymer, being alginates with a higher MM-block content stronger active. As established for other polysaccharides (Ooi \& Liu, 2000), the authors investigated whether macrophage stimulation could be responsible for alginates antitumor activity, however, experimental data failed to confirm this hypothesis (Fujihara \& Nagumo, 1993).

The aim present study is to investigate the in vivo antitumor activity of two alginates with different viscosity extracted from brown seaweed Sargassum vulgare C. Agardh against Sarcoma 180 cells transplanted in mice. The histopathological and morphological analyses of the tumor and the animal organs, including liver, spleen and kidney were performed in order to evaluate toxicological aspects of the alginates treatment.

\section{Experimental}

\subsection{Extraction and purification of alginates}

Specimens of the brown seaweed $S$. vulgare were collected in August/2004 at the Atlantic coast of Brazil (Pacheco Beach, Caucaia, Ceará), cleaned of epiphytes, washed in distilled water and stored at $-20^{\circ} \mathrm{C}$. Alginates were extracted according to the method of Calumpong, Maypa, and Magbanua (1999) with some modifications. The dried algae $(300 \mathrm{~g})$ were extracted at $60^{\circ} \mathrm{C}$, fixed in $2 \%$ formalde- hyde for $24 \mathrm{~h}$, and then washed in water. The thalli were put into $0.2 \mathrm{~N} \mathrm{HCl}$ for $24 \mathrm{~h}$ and washed again in water before extraction with $2 \%$ sodium carbonate. This mixture was homogenized, incubated in a water bath under continuous stirring at temperature of $60^{\circ} \mathrm{C}$ and then two samples were collected after 1 and $5 \mathrm{~h}$ incubation. Crude extracts were collected after the centrifugation of these solutions whose precipitates were discarded, and then, they were precipitated by the addition of ethanol in order to obtain the alginate fractions. These fractions were washed twice in acetone and dried out. The intrinsic viscosities of the two samples obtained were comparatively analyzed, and the alginates obtained after 1 and $5 \mathrm{~h}$ incubation were denominate SVLV (S. vulgare low viscosity) and SVHV (S. vulgare high viscosity), respectively. The alginate fractions (SVLV and SVHV) were purified after dissolving them in distilled water, followed by an ethanol precipitation. The precipitates were then washed twice in acetone and dried out.

The SVLV and SVHV alginates were physico-chemical characterized by Torres (2003). The intrinsic viscosity of SVLV alginate was $5.26 \mathrm{dL} / \mathrm{g}$ while that of SVHV was $9.10 \mathrm{dL} / \mathrm{g}$. The alginates presented different molecular masses, being $19.3 \times 10^{4} \mathrm{~g} / \mathrm{mol}$ that of SVLV and $24.8 \times 10^{4} \mathrm{~g} / \mathrm{mol}$ that of SVHV. ${ }^{1} \mathrm{H}$ NMR spectra have shown the SVLV alginate posses features of a high mannuronic acid (M blocks) content while the SVHV one have shown to be of an intermediary kind (MG blocks). The SVLV alginate had shown a higher proportion of $\mathrm{M} / \mathrm{G}$ (1.38) than the SVHV alginate (1.04).

\subsection{Assay of antitumor activity}

A total number of 185 Swiss mice (female, 20-30 g) obtained from the central animal house of the Federal University of Ceará, Brazil were used. Animals were housed in cages with free access to food and water. All animals were kept under a 12:12 h light-dark cycle (lights on at 6:00 a.m.). Sarcoma 180 tumor cells were maintained in the peritoneal cavities of the swiss mice obtained from the central animal house of the Federal University of Ceará.

Six-day-old Sarcoma 180 ascites tumor cells $\left(5 \times 10^{5}\right.$ cell/ $500 \mu \mathrm{l})$ were implanted subcutaneously into the right hind groin of the mice. One day after inoculation, SVLV and SVHV (50 and $\left.100 \mathrm{mg} / \mathrm{m}^{2}\right)$ or 5 -FU $\left(25 \mathrm{mg} / \mathrm{m}^{2}\right)$ were dissolved in $\mathrm{NaCl} 0.9 \%$ and administered intraperitoneally or orally for 7 days. The negative control was injected with physiological saline. On day 10 , the mice were sacrificed. Tumors, livers, spleens and kidney were extirpated, weighed and fixed in formaldehyde $10 \%$. Inhibition ratio (\%) was calculated by the following formula: inhibition ratio $(\%)=[(A-B) / A] \times 100$, where $A$ is the tumor weight average of the negative control, and $B$ is that of the treated group.

\subsection{Histopathology and morphological observations}

After being fixed with formaldehyde $10 \%$, tumors, livers, spleens and kidney were grossly examined for size or color 
changes and hemorrhage. Then, a portion of the tumor, liver, spleen and kidney were cut into small pieces and later, the histological sections were stained with hematoxylin and eosin. Histological analyses were performed by light microscopy.

\subsection{Ki67 immunohistochemical detection}

Tumor sections were deparaffinized with xylene and dehydrated with ethanol. The slides were then immersed in water for $10 \mathrm{~min}$. For antigen retrieval, the slides were boiled in citrate buffer ( $\mathrm{pH}$ 6.0) for $15 \mathrm{~min}$ in a microwave and subsequently cooled for $20 \mathrm{~min}$. Afterward, the slides were washed in TBS, and then the endogenous peroxidase was blocked by $0.3 \%$ hydrogen peroxide for $15 \mathrm{~min}$. After washing with TBS, the sections were incubated overnight at $4{ }^{\circ} \mathrm{C}$ with mouse antibodies to Ki67 at a concentration of 1:50. After $24 \mathrm{~h}$, the slides were washed and incubated with a multilink antibody for 20 min, washed in TBS and incubated for $20 \mathrm{~min}$ with avidin-biotin-peroxidase complex. After washing with TBS, the slides were incubated for $3 \mathrm{~min}$ with diaminobenzidine, and finally, counter-stained with hematoxylin prior to mounting. The percentage of proliferating neoplastic cells was evaluated directly at the optical microscope. To quantify the amount of proliferation, all Ki67-positive cells were counted in 4-6 random fields per slide.

\subsection{Statistical analysis}

Data are presented as means \pm SEM. The differences between experimental groups were compared by ANOVA followed by Student-Newman-Keuls $(p<0.05)$.

\section{Results and discussion}

\subsection{Antitumor activity}

The search for potential polysaccharides as antitumor agents have gained more attention in the last few decades, since these macromolecules have shown promising immu- nomodulatory properties associated with antitumor effects (Ooi \& Liu, 2000). The enhancement of host defenses is now considered an alternative to the traditional cancer cytotoxic chemotherapy, because it involved lesser side effects.

The aim of the present study was to evaluate antitumor effects of alginates (SVHV and SVLV) isolated from $S$. vulgare and some of the toxicological effects related to their administration. Both alginates inhibited growth of sarcoma 180. The inhibition rates are showed at Table 1. The oral route of administration was more effective for both alginates, leading to an inhibition of $51.8 \%$ and $74.8 \%$ for SVLV at the doses of 50 and $100 \mathrm{mg} / \mathrm{m}^{2} /$ day, respectively, and of $66.2 \%$ and $88.8 \%$ for SVHV at the same doses. SVLV was 2.04 times more active after oral administration, while SVHV was 1.89 , both at the dose of $100 \mathrm{mg} / \mathrm{m}^{2} /$ day. Oral ingestion is the most common method of drug administration, because it is the safest, most convenient, and most economical (Benet, Kroetz, \& Sheiner, 1996). In the cancer area, the availability of chemotherapeutic drugs administrable by oral route represents a step forward in the management of patients (Gebbia \& Puozzo, 2005).

Previous work had discussed the influence of the content of D-mannuronic and L-guluronic acid blocks in alginates antitumor activity (Fujiihara \& Nagumo, 1992, 1993). According to these authors, the higher content of MMblocks in alginate correlate with the higher antitumor activity. The SVLV alginate had shown a higher proportion of M/G (1.38) than the SVHV (1.04). The SVHV alginate showed fractions of $F_{\mathrm{GGG}}=0.214 ; \quad F_{\mathrm{MM}+\mathrm{MG}}=0.667$; $F_{\mathrm{GGM}+\mathrm{MGM}}=0.118$, while the SVLV alginate have shown fractions with $F_{\mathrm{MM}}=0.6$ and $F_{\mathrm{GGG}}=0.4$, and GGM and MGM fractions were not observed (Torres, 2003). Panikkar and Brasch (1996) proposed a classification system with three kinds of alginates based on the monomers composition: alginates with "high $\mathrm{M}$ blocks content" (where, $F_{\mathrm{M}}$ is greater or equal to 0.7 ); alginates with "high $\mathrm{G}$ blocks content" ( $F_{\mathrm{M}}$ is less or equals to 0.6$)$ and intermediate alginates possessing MG blocks ( $F_{\mathrm{M}}$ between 0.6 and 0.7$)$. Based only in this classification system, the SVHV is as an alginate of intermediate type (0.67), while the SVLV (0.6) is as a high G

Table 1

The inhibition rate of alginates (SVLV and SVHV) isolated from Sargassum vulgare on mice transplanted Sarcoma 180 tumor

\begin{tabular}{|c|c|c|c|c|c|c|c|}
\hline Drug & Dose $\left(\mathrm{mg} / \mathrm{m}^{2} /\right.$ day $)$ & Liver (g) & Spleen (g) & Kidney (g) & Tumor (g) & Inhibition (\%) & $N$ \\
\hline Control & - & $1.67 \pm 0.04$ & $0.19 \pm 0.01$ & $0.36 \pm 0.01$ & $2.12 \pm 0.17$ & - & 26 \\
\hline 5-FU & 25 & $1.49 \pm 0.05$ & $0.12 \pm 0.01^{\mathrm{a}}$ & $0.30 \pm 0.01^{\mathrm{a}}$ & $0.51 \pm 0.17^{\mathrm{a}}$ & $75.5 \pm 8.1^{\mathrm{a}}$ & 17 \\
\hline \multirow[t]{4}{*}{ SVLV } & 50 (v.o.) & $1.73 \pm 0.07$ & $0.21 \pm 0.02$ & $0.36 \pm 0.01$ & $1.02 \pm 0.19^{\mathrm{a}}$ & $51.8 \pm 9.2^{\mathrm{a}}$ & 18 \\
\hline & 100 (v.o.) & $1.55 \pm 0.05$ & $0.14 \pm 0.01^{\mathrm{a}}$ & $0.37 \pm 0.01$ & $0.53 \pm 0.13^{\mathrm{a}}$ & $74.8 \pm 6.1^{\mathrm{a}}$ & 20 \\
\hline & 50 (i.p.) & $2.04 \pm 0.07^{\mathrm{a}}$ & $0.31 \pm 0.03^{\mathrm{a}}$ & $0.43 \pm 0.01^{\mathrm{a}}$ & $1.34 \pm 0.22^{\mathrm{a}}$ & $36.8 \pm 10.5^{\mathrm{a}}$ & 15 \\
\hline & 100 (i.p.) & $1.78 \pm 0.06$ & $0.26 \pm 0.02^{\mathrm{a}}$ & $0.36 \pm 0.01$ & $1.34 \pm 0.17^{\mathrm{a}}$ & $36.6 \pm 8.3^{\mathrm{a}}$ & 18 \\
\hline \multirow[t]{4}{*}{ SVHV } & 50 (v.o.) & $1.71 \pm 0.08$ & $0.21 \pm 0.02$ & $0.38 \pm 0.01$ & $0.72 \pm 0.20^{\mathrm{a}}$ & $66.2 \pm 9.7^{\mathrm{a}}$ & 17 \\
\hline & 100 (v.o.) & $1.38 \pm 0.08^{\mathrm{a}}$ & $0.11 \pm 0.02^{\mathrm{a}}$ & $0.30 \pm 0.01^{\mathrm{a}}$ & $0.24 \pm 0.08^{\mathrm{a}}$ & $88.8 \pm 3.8^{\mathrm{a}}$ & 17 \\
\hline & 50 (i.p.) & $1.96 \pm 0.06^{\mathrm{a}}$ & $0.30 \pm 0.02^{\mathrm{a}}$ & $0.41 \pm 0.01^{\mathrm{a}}$ & $1.54 \pm 0.21^{\mathrm{a}}$ & $27.3 \pm 10.0^{\mathrm{a}}$ & 20 \\
\hline & 100 (i.p.) & $1.61 \pm 0.08$ & $0.24 \pm 0.01^{\mathrm{a}}$ & $0.35 \pm 0.02$ & $1.12 \pm 0.18^{\mathrm{a}}$ & $46.9 \pm 8.5^{\mathrm{a}}$ & 17 \\
\hline
\end{tabular}

Data are presented as means \pm SEM from $N$ experiments. Significant differences from control group were evaluated by ANOVA followed Student-Newman-Keuls: ${ }^{\mathrm{a}} p<0.05$. 
block content one. However, the block structure particular to SVLV represented a high content of manuronic acid in opposition to the classification of Panikkar and Brasch (1996). However, contrary to the expectation, SVHV seemed to be slightly more effective than SVLV.

Histopathological analyses of the tumors extirpated from control mice showed groups of large, round and polygonal cells, with pleomorphic shapes, hyperchromatic nuclei and binucleation. Several degrees of cellular and nuclear pleomorphism were seen. Mitosis, muscle invasion and coagulation necrosis were also noticed. In the tumors extirpated from animals treated with 5-FU, SVLV and SVHV, extents areas of coagulative necrosis were observed.

Ki67 staining for cell proliferation was performed in the tumors removed on day 10 from the animals untreated and treated with 5 -FU $\left(25 \mathrm{mg} / \mathrm{m}^{2} /\right.$ day $), \operatorname{SVLV~}\left(100 \mathrm{mg} / \mathrm{m}^{2} /\right.$ day, after oral and intraperitoneal route of administration) or SVHV $\left(100 \mathrm{mg} / \mathrm{m}^{2} /\right.$ day, after oral and intraperitoneal route of administration). Nuclear staining and good preservation of morphological details were observed in all tumors sections immunostained with Ki67 antibody. In some of the examined samples, cells in mitosis showed, in addition to the expected Ki67 chromosomal labeling, also a strong cytoplasmic positivity. Background staining had seen in all the cases. Fig. 1 shows the amount of Ki67 positive cells in the analyzed slides. The results from this analysis show that the relative number of Ki67-positive tumor cells was substantially less in tumors from mice treated with 5-FU, SVHV and SVLV when compared with control tumors $(p<0.05)$.

Immunohistochemical staining of cells for proliferationassociated proteins offers information about the tumor proliferation rate. The monoclonal antibody Ki67, described by Gerdes, Schwab, Lemke, and Stein (1983), is a mouse monoclonal antibody that identifies a nuclear antigen associated with G1, S, G2 and M phases. This molecule is expressed along all cell cycle, except in G0 and early G1 (Gerdes et al., 1984). Thus, results obtained with Ki67 staining showed that the antitumor activities of both SVHV and SVLV are associated with a reduction in the tumor proliferation rate. Moreover, SVHV staining inhibition was higher than SVLV, corroborating the observed in tumor weight $(p<0.05)$.

\subsection{Toxicological effects}

After the treatment with alginates SVHV and SVLV $(25 \mathrm{mg} / \mathrm{kg} /$ day $)$, the kidney, livers and spleens weights were significantly altered $(p<0.05$, Table 1$)$. As expected for a chemotherapeutic drug, 5-FU treatment resulted in liver, spleen and kidney weight decreasing $(p<0.05$, Table 1$)$.

The spleens removed from control mice showed normal and preserved white pulp, and megakaryocytes with hyperlobulated nuclei without morphologic alterations (Fig. 2A). In contrast, alginates, especially SVHV when orally injected, led to a hyperplasia of white pulp in the spleen of treated animals (Fig. 2C), which suggests an immunostimulant activity of these compounds. The hematopoiesis occurs in spleen mainly during the neonatal life, however its hematopoietic ability is preserved during the whole life (Banks, 1992; Coelho, 2002). The alginates observed antitumor activity seems to be related to the enhancement of host defenses, since the studied alginates failed to exhibit direct cytotoxicity against tumor cell lines in culture (data not shown). In fact, it is postulated that the antitumor activity of polysaccharides is associated with their immunomodulatory properties (Ooi \& Liu, 2000). As previously mentioned, in the case of alginates, the literatures remains controversy. It is also observed a discrete dysmegakaryopoiesis in alginates treated animals (Fig. 2D), however there is no alteration in the number of circulating platelets (data not shown). Most chemotherapy drugs, including 5-FU, are

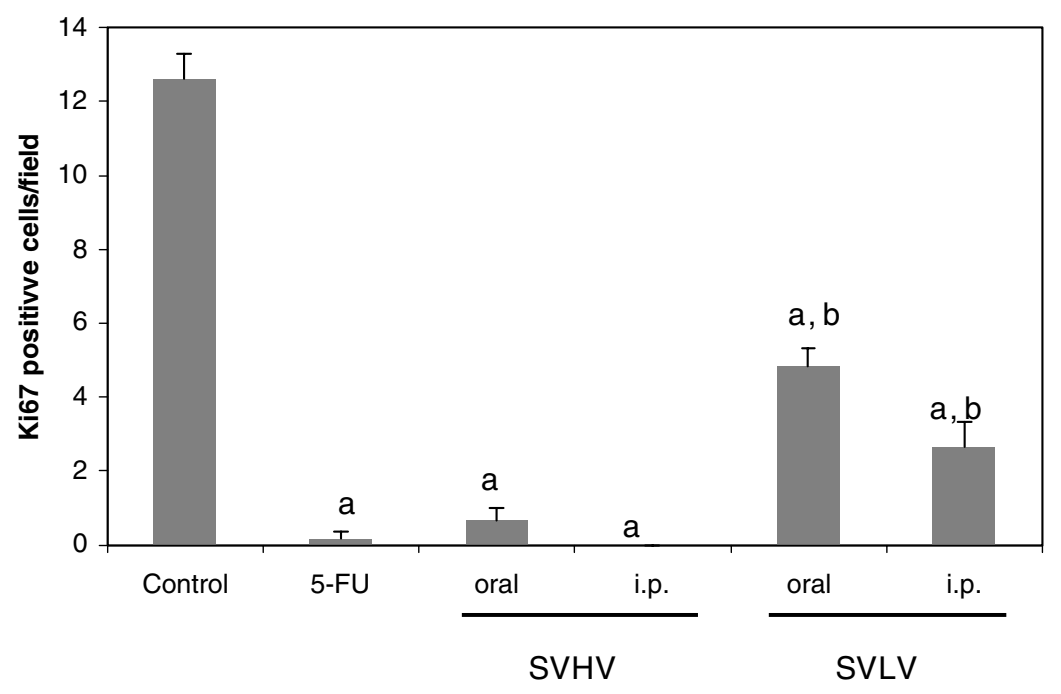

Fig. 1. Effect of 5-FU, SVHV and SVLV (100 mg/m²/day) on Sarcoma 180 cell proliferation using Ki67 antibody. Ki67-positive cells from 4 fields/tumor were counted, and the mean \pm SEM of positive cells was calculated. a, $p<0.05$, compared to control, and b, $p<0.05$, compared to 5-FU, ANOVA followed by Student-Newman-Keuls. 
immunosuppressive and have negative side effects (Takiguchi et al., 2001). Indeed, in 5-FU treated animals, it was observed hypoplasia of white pulp and small lymphoid aggregates as well as megakaryocytes (Fig. 2B).

Histopathological analyses of the kidneys from both SVLV and SVHV-treated animals showed several degrees of hydropic changes and vacuolization of the cytoplasm of proximal tubular epithelium and glomerular and tubular hemorrhage, but the glomeruli structure was essentially preserved. These finding were observed in treated animals despite the administration route used. Moreover, the cells lining the tubules of kidney removed from SVLV-treated animals (50 and $100 \mathrm{mg} / \mathrm{m}^{2} /$ day), only after intraperitoneal injection, are necrotic (Fig. 3). This necrosis is characterized by no nuclear staining and a deeply eosinophilic cytoplasm
(Curran, 1990). Thus, SVLV could be considered more toxic to the kidney.

Necrosis of the epithelium of the renal tubule may occur on a large scale as a consequence of different classes of chemicals administration (Olsen \& Solez, 1994). The consequence is sudden onset of anuria or severe oliguria and acute renal failure. However, the epithelium has a considerable power of regeneration and renal function can be stored. Despite the intensity of the cell damage, the regeneration depends also on the integrity of the interstitial tissues (Curran, 1990; Olsen \& Solez, 1994). It is worthwhile to mention that the histopathological analyses of SVLV treated animals demonstrated that the interstitial tissues are preserved, without edema or lymphocyte infiltration, which suggest the possibility of regeneration.
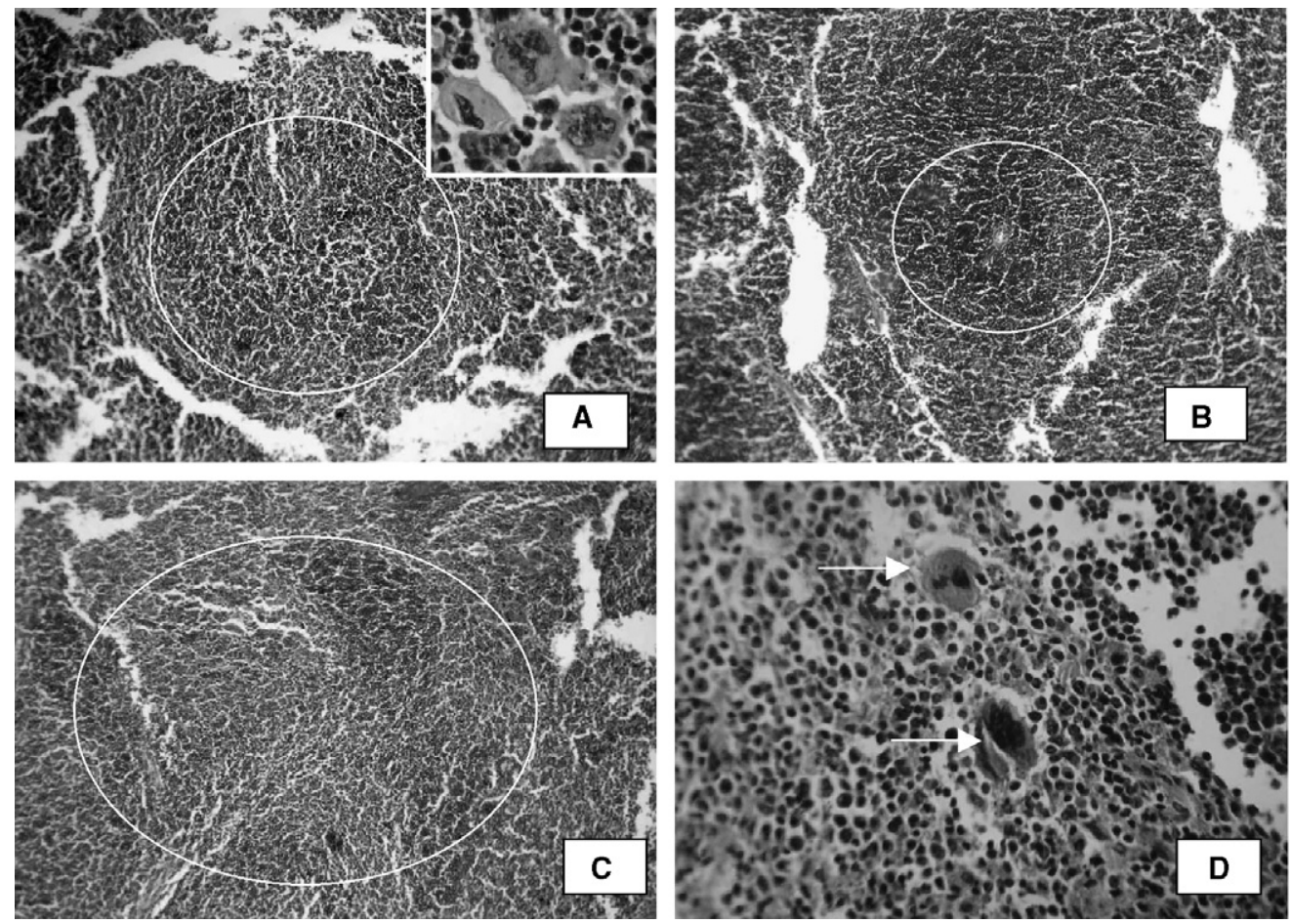

Fig. 2. Histopathology of the spleen from mice transplanted Sarcoma 180 tumor. (A) Control group; (B) $5-\mathrm{FU}$ ( $25 \mathrm{mg} / \mathrm{m}^{2} / \mathrm{day}$ ); (C) SVHV (100 mg/m²/day, v.o.) treated group. The detail of (A) shows the megakaryocytes on the spleen of control mice. White arrows indicate the megakaryocytes in the spleen of SVHV-treated animals. The white circles delineate the white pulps.
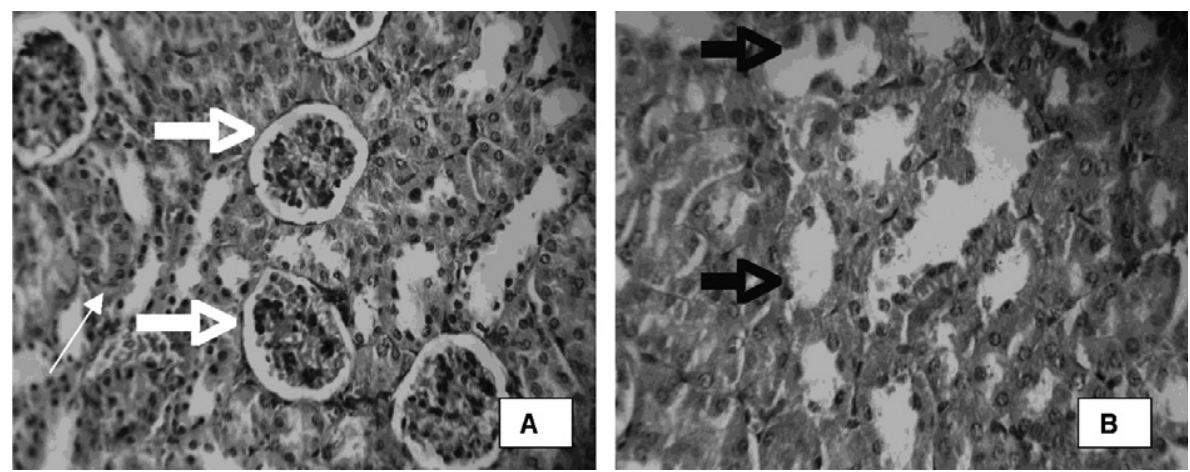

Fig. 3. Histopathology of the kidney from mice transplanted Sarcoma 180 tumor. (A) Control group; (B) SVLV (50 mg/m²/day, i.p.) treated group. Thick white arrows indicate the glomeruli structure and thin white arrows indicate normal tubular cells. Black arrows indicate necrosis of the cells lining the tubules. 
Despite the observed effects in kidneys, the histopathological analyses indicated that the liver was also a target organ for alginates toxicity. The observed effects included Kupffer cells hyperplasia, portal tracts and centriolobular vennus congestion, focal infiltrate of chronic inflammatory cells, intense ballooning degeneration of hepatocytes, sinusoidal hemorrhage and focal areas of steatosis microvesicular. These effects were observed in all treated-animals.

The drugs should be considered as a possible cause of any liver lesion found on a biopsy. A large number of drugs of different chemical structure and with widely differing pharmacological actions occasionally give rise to important liver lesions (Scheuer \& Lefkowitch, 2000). Incriminated substances include antituberculous drugs, non-steroidal anti-inflammatory drugs, anaesthetics, herbal remedies, methotrexate, chlorinated hydrocarbons and many others (Kummar, Abbas, \& Fausto, 2004; Rang \& Dale, 1991; Scheuer \& Lefkowitch, 2000). Regardless, the liver shows great adaptive and regeneration abilities. For example, the increase in endoplasmic reticulum produced by long-term treatment with anticonvulsant drugs is commonly regarded as an adaptive phenomenon. On the other hand, regeneration of hepatic tissues occurs in many diseases, except in the most deleterious ones. Even when the hepatocellular necrosis is present, but the conjunctive tissue is preserved, the regeneration is almost complete (Kummar et al., 2004; Scheuer \& Lefkowitch, 2000). The hepatic alterations observed after alginates treatment could be considered reversible (Kummar et al., 2004; McGee, Isaacson, \& Wright, 1992; Scheuer \& Lefkowitch, 2000).

\section{Acknowledgements}

The authors are grateful to the Brazilian Agencies FINEP, CAPES, CNPq, BNB/FUNDECI, PRONEX, and FUNCAP for fellowship and financial support. Silvana França dos Santos and Francisco José Queiroz de Oliveira provided excellent technical assistance.

\section{References}

Banks, W. J. (1992). Histologia Veterinária Aplicada. São Paulo: Editora Manole Ltda.

Benet, L. Z., Kroetz, D. L., \& Sheiner, L. B. (1996). Pharmacokinetics. The dynamics of drug absorption, distribution and elimination. In J. G. Hardman, L. E. Limbird, P. B. Moliniff, R. W. Ruddon, \& A. G. Gilman (Eds.), Goodman \& Gilman's The pharmacological basis of therapeutics (pp. 3-28). New York: The McGraw-Hill Companies, Inc.

Blunden, G. (1993). Marine algae as sources of biologically active compounds. Interdisciplinary Science Reviews, 18, 73-80.

Calumpong, P. H., Maypa, P. A., \& Magbanua, M. (1999). Population and alginate yield and quality assessment of four Sargassum species in Negros Island, central Phillipines. Hydrobiologia, 398/399, 211-215.

Coelho, H. E. (2002). Patologia Veterinária. São Paulo: Editora Manole Ltda.

Curran, R. C. (1990). Color atlas of histopathology. New York: Oxford University Press.

Darquy, S., \& Sun, A. M. (1987). Microencapsulation of parathyroid cells as a bioartificial parathyroid in vitro studies. ASAIO Journal, 33, 356358 .
Fan, M. Y., Lum, Z. P., Fu, X. W., Levesque, L., Tai, I. T., \& Sun, A. M. (1990). Reversal of diabetes in BB rats in transplantation of encapsulation pancreatic islets. Diabetes, 39, 519-522.

Fujiihara, M., Izimma, N., Yamamoto, I., \& Nagumo, T. (1984). Purification and chemical and physical characterization of an antitumor polysaccharide from the brown seaweed Sargassum fulvellum. Carbohydrate Research, 125, 97-106.

Fujiihara, M., \& Nagumo, T. (1992). The effect of the content of D-mannuronic acid and L-guluronic acid blocks in alginates on antitumor activity. Carbohydrate Research, 224, 343-347.

Fujiihara, M., \& Nagumo, T. (1993). An influence of the structure of alginate on the chemotactic activity of macrophage and the antitumor activity. Carbohydrate Research, 243, 211-216.

Gebbia, V., \& Puozzo, C. (2005). Oral versus intravenous vinorelbine: clinical safety profile. Expert Opinion on Drug Safety, 4, 915-928.

Gerdes, J., Lemke, H., Baisch, H., Wacker, H. H., Schwab, U., \& Stein, H. (1984). Cell cycle analysis of a cell proliferation associated human nuclear antigen defined by the monoclonal antibody Ki-67. Journal of Immunology, 133, 1710-1715.

Gerdes, J., Schwab, U., Lemke, H., \& Stein, H. (1983). Production of a mouse monoclonal antibody reactive with a human nuclear antigen associated with cell proliferation. International Journal of Cancer, 31, $13-20$.

Ireland, C. M., Copp, B. R., Foster, M. P., McDonald, L. A., Radisky, D. C., \& Swersey, C. (1993). Biomedical potential of marine natural products. In D. H. Attaway \& O. R. Zaborsky (Eds.), Marine biotechnology: Pharmaceutical and bioactive natural products (pp. 1-37). New York: Plenum Publishing Corporation.

Kimura, Y., Watanabe, K., \& Okuda, H. (1996). Effects of soluble sodium alginate on cholesterol excretion and glucose tolerance in rats. Journal of Ethnopharmacology, 54, 47-54.

Kummar, V., Abbas, A., \& Fausto, N. (2004). Robbins \& Cotran pathology basis of disease. China: WB Saunders.

McGee, J. O. D., Isaacson, P. A., \& Wright, N. A. (1992). Oxford textbook of pathology: Pathology of systems. New York: Oxford University Press.

Moe, S. T., Draget, K. I., Skjåk-Bræk, G., \& Smidsrød, O. (1995). Alginates. In A. M. Stephen (Ed.), Food polysaccharides (pp. 245-286). New York: Marcel Dekker, Inc.

Olsen, S., \& Solez, K. (1994). Acute tubular necrosis and toxic renal injury. In C. C. Tisher \& B. M. Brenner (Eds.), Renal pathology: With clinical and functional correlations (pp. 769-809). Philadelphia: J.B. Lippincott Company.

Ooi, V. E. C., \& Liu, F. (2000). Immunomodulation and anti-cancer activity of polysaccharide-protein complexes. Current Medicinal Chemistry, 7, 715-729.

Otterlei, M., Ostgaard, K., Skjak-Braek, G., Smidsrod, O., Soon-Shiong, P., \& Espevik, T. (1991). Induction of cytokine production from human monocytes stimulated by arginate. Journal of Immunotherapy, 10, 286291.

Panikkar, R., \& Brasch, D. J. (1996). Composition and block structure of alginates from New Zealand brown seaweeds. Carbohydrate Research, 293, 119-132.

Rang, H. P., \& Dale, M. M. (1991). Pharmacology. Hong Kong: Churchill Livingstone.

Renn, D. W. (1997). Biotechnology and the red seaweed polysaccharide industry: status, needs and prospects. Trends in Biotechnology, 15, 914.

Ronghua, H., Yumin, D., \& Jianhong, Y. (2003). Preparation and in vitro anticoagulant activities of alginate sulfate and its quaterized derivatives. Carbohydrate Research, 52, 19-24.

Scheuer, P. J., \& Lefkowitch, J. H. (2000). Drugs and Toxins. In P. J. Scheuer \& J. H. Lefkowitch (Eds.), Liver biopsy interpretation (pp. 134-150). London: WB Saunders.

Smit, A. J. (2004). Medicinal and pharmaceutical uses of seaweed natural products: a review. Journal of Applied Phycology, 16, 245-262.

Son, E. H., Moon, E. Y., Rhee, D. K., \& Pyo, S. (2001). Stimulation of various functions in murine peritoneal macrophages by high mannuronic 
acid-containing alginate (HMA) exposure in vivo. International Immunopharmacology, 1, 147-154.

Soon-Shiong, P., Henitz, R. E., Merideth, N., Yao, Q. X., Zheng, T., Murphy, M., et al. (1994). Insulin independence in a type I diabetic patient after encapsulated islet transplantation. Lancet, 343, 950-951.

Takiguchi, N., Saito, N., Nunomura, M., Kouda, K., Oda, K., Furuyama, N., et al. (2001). Use of 5-FU plus hyperbaric oxygen for treating malignant tumors: evaluation of antitumor effect and measurement of 5-FU in individual organs. Cancer Chemotherapy Pharmacology, 47, $11-14$.
Thomas, A., Harding, K. G., \& Moore, K. (2000). Alginates from wound dressings activate human macrophages to secrete tumour necrosis factor- $\alpha$. Biomaterials, 21, 1797-1802.

Torres, M.R. (2003). Purificação, caracterização físico-química, atividades inflamatória e imunoadjuvante de alginatos da alga marinha Sargassum vulgare C. Agardh. Tese apresentada a Coordenação do Curso de Pós-Graduação em Bioquímica da Universidade Federal do Ceará.

Tze, W. J., \& Tai, J. (1982). Biocompatibility and immunological studies of microencapsulation with cross-linked alginate capsules. Transplantation, 33, 563-564. 